\title{
Metaphor Making Through the Body
}

Kenneth J. Shapiro

Bates College

The thesis of this paper is that a sensitivity to the body is a helpful way of generating metaphor. By the body I mean the lived body, the body as we experience it. Generating metaphors refers to creating or producing metaphor as distinguished from comprehending already existing metaphor. The context in which I will discuss the generation of metaphor is that of conducting human science research, although it might equally apply to writing poetry.

As defined in a literary context, a metaphor is a statement which equates two apparently disparate phenomena-as, for example, a person is a fruit or love is a rose. A metaphor is a statement of the form "A is a B." The formal equation is of two entities so different that they do not share literal, that is, dictionary meaning, but do share nonliteral, nondictionary, or figurative meaning. There is nothing of botany in the dictionary entry for love, yet love and rose share many attributes or structures or constitutive conditionsboth are beautiful, both can be painful, both perhaps need to be tended and so forth, inexhaustively. The two explicit terms of the metaphor are called the subject (love) and the predicate (rose). The implicit shared nonliteral meanings are called the ground of the metaphor (e.g., beauty).

\section{Competing Accounts}

There are a number of competing accounts of how we comprehend metaphor. I will treat them selectively and sketchily to highlight some of the problems peculiar to an account of how to generate metaphor, our primary concern here. According to Richards (1936), the act of comprehending a metaphor involves a tension in the listener created by his or her noticing the literal incompatibility of the subject and the predicate. Hearing "a person is a fruit" pushes me, as it were, to attempt to make sense of that statement beyond the confines of the dictionary meaning of person. However, I do not believe such tension is necessarily present, even in the comprehension of metaphor. Often we understand a metaphor without noticing the literal incompatibility, that is, without noticing that the meaning we gained is metaphoric. In any case, to generate a metaphor, in contrast to comprehending a metaphor, tension cannot be an initial step for we have only the subject and we seek a metaphoric predicate. Subject and predicate have not yet been coupled to produce a tension. 
According to Yoos (1971), to understand a metaphor we must conceive or imagine something as something else-a person as a fruit. According to most accounts, in order for us to do that in a way that is meaningful, the two entities must be similar-they must share nonliteral meanings. To comprehend a metaphor, then, is to apprehend similarity. How do we know similarity? A cognitive-style theory conceives of knowing similarity through a listing of the meaning or semantic features of the subject and the predicate and then scanning the two lists for matches. The matches, the nonliteral meanings in common, are the ground of the metaphor. This attribute matching comparison theory makes no experiential claim, that is, there is no concern with the awareness or experience of the individual in the theory. Rather, mental processes such as listing and scanning (built, by the way, on the metaphor "a person is a computer") occur unconsciously. From my point of view, this begs the question of how we experience similarity. As problematically for a qualitative approach, the notion of matching seems to assume that the similarities are simple adjectival attributes. But the grounds of a metaphor are often much more complex - for example, "love's joy hides its burdens as the rose's blossom conceals its thorn." It seems cumbersome to theorize that such complex structural relations, such worlds, exist in some semantic listing which is readily scannable.

Other theories are less cognitive, semantic, and analytic in style and allow the direct perception or the imagination of similarity. For example, Werner and Kaplan (1963) describe a theory of metaphor involving physiognomic perception. In this modality, relations or structures in common between a subject and predicate are perceived immediately, without first attending to literal incompatibility and without listing matching attributes. Relations are seen or imagined directly, without linguistic mediation.

This is closer to the current thesis but does not yet provide a description of the role of the body in the perception or imagination of similarity. Again, to generate a metaphor we cannot simply directly perceive similarity for the predicate is not yet present.

\section{Metaphor Generation}

Let us turn more directly to the problem of metaphor generation. There is a family of theories of metaphor which stretches the notion that metaphor is based on similarity, that a metaphor has a ground consisting of common meanings. A couple of years ago, while browsing, I leafed through a book of poetry written by a computer programmer-not in his off-hours. The author devised a program consisting of a list of subjects and predicates, with the only stipulation that one is able to visualize the predicates more or lessa giant, gnarled oak tree rather than a form of democratic socialism. The subjects and predicates were randomly selected, listed, and paired. With only minor transitions and variable phrasing added, 
the subsequent text passed as highly metaphoric poetry. Try it. Take love as subject and pick random predicates. You will be surprised that virtually all pass as metaphor and, indeed, some are "really deep." To the degree that this device for generating metaphors may be said to work, it begins to suggest that the ground of a metaphor is not a set of already constituted similarities. The claim might be made that, given only the random pairing, we, the listener, create the similarity. If this is the case, the problem of generating metaphor virtually collapses, at least as I have framed the question in terms of the apprehension or discovery of similarity.

Roughly speaking, this is the theory associated with Black (1962), among others. Interaction theory, as it is called, asserts that a metaphor itself is the occasion of the creation of novel meanings that surpass any present common meaning of subject and predicate. "Metaphor creates similarity rather than (formulating) similarity previously existing" (Haynes, quoted in Ortony, Reynolds, \& Arter, 1978). A metaphor pairing river and mouth, "the river has a mouth," gives the river a mouth for the first time. This postmodernist style of theory gives a primacy to language beyond even the cognitive theory described earlier. That the river has a mouth does not necessarily reflect any homologous function of the two entities-river and mouth; or even any feature common to our lived experience of the twothat, for example, we take in nourishment or transport goods at this part or location of both. This theory valorizes both the primacy and the innovative power of language. Metaphor is from the outset purely a linguistic phenomenon and metaphor is the lexical extender par excellence - the builder and mover of linguistic usage. The dictionary grows as metaphors are created, used more and more often, and eventually become dead metaphors. Even once created, a metaphor has the fluidity of growth in meaning of any text. It is subject to further and new interpretation. This theory is consistent with the general thrust of Paul Ricoeur's philosophy of culture-although he gives less primacy to language per se. The culture has a certain semi-autonomous growth. Individual development and identity formation are functions of the assimilation or taking up of those cultural meanings currently available. This is a long way from the classical Aristotelian notion that figures of speech, notably metaphor, are rhetorical devices in the degraded sense of that term, mere adornments that add no meaning; they are merely stand-ins or substitutes for already established meaning. The mouth in "the river has a mouth" does not add any meaning. Mouth is just a fancy way of saying outlet in that classical account.

\section{The Lived Body as Ground}

The present thesis distinguishes itself from a purely semantic or linguistic theory by emphasizing the experiential and, specifically, the lived bodily basis of the apprehension of similarity and, therefore, of 
the ground of metaphor. In terms of the innovativeness of metaphoric meaning it takes a middle position between the Aristotelian denial of novel meaning and the postmodern notion that metaphoric meaning creates itself through the semantic interaction of subject and predicate. I am not denying that interaction is a generative feature of an already constituted metaphor, but I am denying that it is helpful in the original creative act of generating a metaphor.

Let me begin to develop that thesis more directly now, by setting it in the context of the role and possible usefulness of metaphor generation in human science research. First, let me establish a fuller reference for the lived body. The use of that and related terms is an elaboration of those of Marcel, Merleau-Ponty (1962), Sartre (1966), Gendlin (1962), and Langer (1954). ${ }^{1}$ To exemplify the scope of the lived body, through the lived body I know the different moves that I might make on a jungle gym, and the vantage points gained having made each; through the lived body I have a sense of the next play on the squash court. But also through the lived body, I am sensitive to interpersonal situations-I know how to respond to you before I have the words to do so or can say to myself what is going on; I appreciate the changing shape of our relation through it. Extending its protean powers even more, through the lived body I have a sense of the shape of this present argument, and, more generally, a sense of the shape and structure, the kinetics, dynamics, and architecture of ideas-to the degree that they are meaningful to me.

For Merleau-Ponty the lived body is the ground of the possibility of perception. To perceive something is to live in it, to bodily inhabit it. To see the lamp on the table is to virtually take up its vantage point as if it could see. To experience is to bodily inhabit an object in the world and thereby co-constitute its structure or meaning. Structure has a presence in the phenomenal field which we apprehend through a behavioral mode, by a kind of enactment of the structure. Further, this embodiment of structure in the lived moment is available in reflection as a bodily sense of the structure of a phenomenon. In the aftermath of living it, the body, as it were, carries the structure of a moment away with it and, in fact, the lived body consists of such structures. In this way the body is the locus or bearer of prelinguistic meaning. Following Gendlin (1978), to make meaning explicit, to put experience into words, we can focus on the bodily pole of experience.

With regard to metaphor, we must show that this bodily sense of structure is the ground of metaphor. In particular, with regard to metaphor generation, we must show how a potential predicate is any entity which invites this particular bodily sensed structure to be enacted precisely because it shares this structure in common with the subject of the metaphor. Metaphor involves disparate phenomena which have structures in common. This notion of the lived body 
means that they, then, have a bodily sense in common. Attendance to this bodily sense of structure can yield predicates.

An example from the work of Piaget is helpful. Consider his observation of Lucienne at the age of one year, four months:

Lucienne at first fails to free a watch chain from a matchbox in which Piaget has lodged it. After these initial efforts at groping with her fingers to reach the chain through the presently insufficient opening in the box, she looks at the slit for a moment and then several times in succession, she opens and shuts her mouth, at first slightly, then wider and wider. With this, she then immediately removes the chain by enlarging the opening. (Ginsburg \& Opper, 1969)

The child solved the problem. What did she need to know to solve it? Clearly, she needed to appreciate the structure of the situationthat the relation between the matchbox and the watch chain is that the latter is in the former and is presently constrained by the given relation of its two parts and that by enlarging the opening the chain is freed.

How does she know that structure, by what modality of experience? Obviously, at her age, she does not have linguistic categories through which to conceptualize the situation. She imitates the potential motion of the matchbox through possible moves of her own body. She knows the relations through her body-through a sense of how she can move and through a "natural analogy," to use Langer's (1954) term, between her possible movement and the possible movement of the matchbox enclosing the chain. The opening of the child's mouth is an imitation of a structure, here the relation we might explicate by the term "enlarge by opening." Structures are dynamic. They consist of pushes and pulls, of possible motions, of forces at play. Therefore, they must be known by living them, by acting them out. Apprehension of structure is intimately related to possible moves of the body as this example clearly shows. Later in development, observable bodily enactment of structure gives way to unobservable, virtual enactment. But the lived body remains a primary vehicle of our understanding of situations and concepts.

This example shows how it is the lived body that originally takes up, lives, and thereby prelinguistically co-constitutes the structure of situations; how the lived body can, for Piaget, imitate, for MerleauPonty, inhabit, those dynamic shapes and forces that are the bases of meaning. However, it does not yet show how the lived body is the ground of metaphor. In fact, the example is perhaps misleading in that regard. It suggests that the body is the predicate not the ground. We have here the admittedly weak metaphor-the matchbox is Lucienne's mouth. Incidentally, this is an approach to a phenomenology of symptom formation. When a situation is stressful or overtaxing, for example, it is lived bodily as a pain in the neck or a headache. Particularly when one refuses to acknowledge that stress, 
it eventually establishes itself as a headache-with the occasioning circumstances forgotten.

To show how the body can be the ground rather than the predicate of metaphor we need to describe, first, how it carries structures; how, through the body, structures of situations are available in the aftermath of our living them; and, then, how these bodily available structures can help us pair entities that have some structures in common and are then metaphors.

Consider the following cinematic excerpt:

In the film Modern Times, Charlie Chaplin's work on the factory assembly line consists of one very repetitious act, tightening a series of nuts with a wrench. By the end of the day this act is so engrained in Charlie that he seems to see most situations as offering nuts to be tightened. $\mathrm{He}$ tightens the fire hydrant's bolted top and yarious other nut-like objects until, of course, he gets to the policeman's jacket and the chase begins.

What is going on here? Charlie finds a world which invites the continued application of his limited repertoire. As we watch him, he continually reenacts the same situation-a certain structure consisting of self as bolter and other as to-be-bolted.

In the terms of our analysis, his behavior embodies a certain structure again and again. He carries that structure as a bodily sense of a certain move. It is as if he is primed or set-there is a certain readiness or inclination of his body. We assert here the general availability of this possibility. Any structure, a structure of anger, of depression, of being in private, of being criminally victimized, of closeness or intimacy, of being in a certain kind of group, of a certain concept, can be bodily and prelinguistically carried, for it is originally a certain dynamic form or shape which the body once took, embodied, and enacted, and of which now the body is informed. In reflection we can be sensitive to it. As we attend to our body we find that any structure has a presence and that we are aware of it precisely as a bodily sense of a certain possible move.

If the body carries and in fact consists of structures, then it can be the vehicle that helps us to notice and then link apparently disparate phenomena that yet have structures in common. This act generates metaphor. They can be crude metaphors, as in the Chaplin example, based on a rough common gestalt, or more interesting and novel metaphors.

\section{Uses of Sensitivity to the Lived Body}

In the context of conducting qualitative research, we can indicate three possible uses of sensitivity to this bodily pole of our experience. The first, although it involves sensitivity to the body and is helpful in describing phenomena under investigation, we will argue does not produce metaphor. Let us consider the three possible moves in turn, using the example of a study of depression. 
Interviewing a subject, he or she says to me, "When I am depressed I feel empty." Consider, then, "Depression is emptiness." Is this a metaphor? It is not strictly of the form "A is a B," but it arguably has the form of a metonymy, a figure of speech closely related to metaphor. It is a metonymic statement if empty is an abbreviated way of saying an empty something, like an empty bottle. But does the subject intend to say that depression is like something else that is also empty, and should we, then, as investigators providing a description of depression, intend that comparison? Here the subject has no such intention. Further, in general, phenomenological description is not metaphoric-although it can effectively utilize metaphor, as we will describe. The descriptive "I am empty" is directly expressive of the experience of depression. While the word empty may not appear in a dictionary definition of depression, the term is literal in that empty does not refer to some second entity distinct from depression. It is intended precisely to refer to a constitutive feature of depression. Empty is a direct explication of how the body is in depression. In general, phenomenological description is literal in this sense, although the uninitiated often take much of its description as metaphoric and, further, of course, take metaphoric description as less than rigorous. The first use of sensilivity to the lived body, then, is to explicate it- to describe to yourself or to facilitate your subject's description of how his or her body feels in depression. I will not deal here with interviewing techniques that facilitate this bodily sensitivity, but Gendlin's (1978) work is a required beginning point.

The second use helps me, or allows me to help, subjects to return to further instances of the phenomenon in interest. It also generates metaphor, although metaphors that are, from a literary point of view, not very interesting. Being sensitive to the lived bodily pole of a phenomenon under investigation opens the subject, or primes the subject, to discover, memorially, imaginatively, or perceptually additional instances of the target topic. As the Chaplin example coarsely but dramatically suggests, sensitivity to the body activates a certain set of structures and, in turn, leads the subject to intend situations that embody them. Being sensitive to the bodily sense of depression, a subject is more likely to notice or recall, for example, the chair in which the lost object is no longer seated. The subject states, "When I am depressed, I see your empty chair." We then have the unequivocally metaphoric descriptive: Depression is an empty chair. Here, methodologically, sensitivity to the body is clearly helpful in two ways-first, as a device to facilitate the return to a phenomena as lived, in Husser?'s sense- to get the subject directly back into instances of the phenomena. Second, it provides metaphoric description. However, I have suggested that such metaphor is not very interesting. It is not interesting because it is built on two entities that, although distinguishable, are not strikingly disparate. An 
empty chair is an immediately recognizable and poignant example of the general phenomenon of depression. Our expressing their pairing in a metaphoric form is a rhetorical device. As subjects and investigators, we have probably already noticed that they share certain structures in common.

A third possible move, given a sharpened sensitivity to the bodily pole of experience, adds a richer use of metaphor both for the exploration of the target phenomenon, and as an aid in its eventual description. Not entirely incidental to our concerns as human science researchers, it facilitates the creation of relatively novel metaphors.

Consider the following: I am focusing on the bodily sense of depression, particularly on the sense of my body as empty. Suddenly I have an image of myself in a theater after the performance is over and the audience has left. With this image I have the metaphoric statement- "In depression I am in an empty theater." How do we understand this sequence? Our argument, again, is that the experience of an empty theater has some structural features in common with depression as a phenomenon and hence resonates with the bodily sense of its structure. I find the image "empty theater" for it has common bodily correlates with depression. I have made some of the same moves when depressed as when in an empty theater. To illustrate, I miss the world of the play now ended, a world which, to the degree that the play was engaging, I had entered, joined, become. Now it has suddenly collapsed and I find myself hesitating to leave, as it were, without it, reluctant or even unable to resume without it for its absence is distracting. These are clearly aspects of a depressive posture here. On the other hand, this quickly passes for I had made no real commitment to it; it was only a play. But how do we know that being in an empty theater is not simply another example of being depressed as in the previous possibility, that I have returned to it much as when I am likely to recall various other occasions of my being depressed? Perhaps the metaphor is merely built from that now remembered occasion.

We are arguing that the theater after a performance is clearly a disparate phenomenon while the chair without the object of grief seated in it is an instance of depression and that a more striking and original metaphor making occurs when the predicate discovered is clearly a disparate phenomenon. In general, how do we know the difference phenomenologically between these two possibilities? I am focusing on an aspect of depression, and the image of the theater after a performance emerges. On reflection, I find I have two feelings about this-one is that I sense a certain resonance which is the bodily sense of their common features. Second, however, I am initially surprised and puzzled that that focus led me to that image. When the emergent image or discovered situation is simply another instance of the focal phenomenon, there is not this surprise. I am not surprised that when depressed I am reminded of or notice your now 
empty chair. In fact, part of my being depressed is precisely anticipating and seeing nothing but signs of your absence. Note that the sequence here in this act of generating a metaphor is different than in the comprehension of a metaphor. There I often first feel the tension or puzzlement at the literal incongruity of subject and predicate-a person is a fruit. I resolve it by the discovery of a metaphoric congruity - that a person is crazy. Here I first discover the congruity through the common bodily sensed structures; first I feel the resonance and only then am I struck by the fact that the two entities are strange bedfellows.

In regard to metaphor generation, we are arguing that sensitivity to the bodily presence of a structure is a highly effective path to making metaphors. While metaphors can be found through word association, through language without recourse to the phenomena as lived, the discovery of a fresh metaphor is more likely if we bypass pairs of entities already linguistically associated. Random linguistic pairings can generate metaphor but they are less likely to satisfy or inform the pairings based on lived bodily structures in common. The initial innovativeness of metaphors generated in this third possible bodily way is limited to noticing for the first time that they have structures in common. Of course, once the metaphor is in place, it is like any text-open-ended and inexhaustible in the innovativeness of subsequent readings.

In regard to the human science investigatory process, the discovery of a disparate entity sharing structures with the target phenomenon provides an excellent opportunity for comparative analysis. Locating a certain structure or structures of the target phenomenon in a tropological space disembeds and isolates such structures. This fresh examination of them helps distinguish constitutive or essential parts of the target phenomenon. Further, a tandem exploration of the target phenomenon and the predicate of the generated metaphor can provide a descriptive framework for the eventual account of the target phenomenon. Metaphor production provides both a useful investigatory tool for working with subjects and an ancillary set of comparisons that very likely vivify, given their shared experiential bases, the narrative account of the phenomenon under study. Promoting and utilizing bodily sensitivity enhances the investigative process and its product in human science research.

\section{Note}

1. More recently, the lived body is back in the saddle, again, being featured in works by Zaner (1981) on the self, Levin (1985) in an attempt to give Heiddegger a body, O'Neill (1985) on the social construction of the body, Sacks (1984) in a phenomenological neurology, and myself (Shapiro, 1985) applying sensitivity to the body to a phenomenological method. 


\section{References}

Black, M. (1962). Models and metaphors: Studies in language and philosophy. Ithaca, NY: Cornell University Press.

Gendlin, E. (1962). Experiencing and the creation of meaning. Toronto: Free Press.

Gendlin, E. (1978). Focusing. New York: Everest House.

Ginsburg, H., \& Opper, S. (1969). Piaget's theory of intellectual development. Englewood Cliffs, CA: Prentice-Hall.

Langer, S. (1954). Feeling and form. New York: Scribner.

Levin, D. (1985). The body's recollection of being. London: Routledge \& Kegan Paul.

Merleau-Ponty, M. (1962). Phenomenology of perception. New York: Humanities.

O'Neill, J. (1985). Five bodies: The human shape of modern society. Ithaca, NY: Cornell University Press.

Ortony, A., Reynolds, R., \& Arter, J. (1978, September). Metaphor: Theoretical and empirical research. Psychological Bulletin, 85, 5.

Richards, I.A. (1936). The philosophy of rhetoric. London: Oxford University Press.

Sacks, O. (1984). A leg to stand on. New York: Harper \& Row.

Sartre, J. (1966). Being and nothingness. New York: Washington Square Press.

Shapiro, K. (1985). Bodily reflective modes: A phenomenological method for psychology. Durham: Duke University.

Werner, H., \& Kaplan, B. (1963). Symbol formation. New York: Wiley.

14 Yoos, G. (1971). A phenomenological look at metaphor. Philosophy and Phenomenological Research, 32,78-88.

Zaner, R. (1981). The context of self: A phenomenological inquiry using medicine as a clue. Athens, $\mathrm{OH}$ : Ohio University Press. 